\title{
Anthropological translation: A semiotic definition
}

\section{Massimo Leone}

Drawing from Hjelmslev's theory of language, the article proposes a typology of translation difficulties, claiming that the most insurmountable one relates to cultural patterns that are invisible to cultures themselves. As a solution, the article suggests the establishment of a semiotic variety of translation, exemplified through a pair of case studies. Verses 22-45 of Canto XXVIII of Dante Alighieri's Inferno are usually problematic for Muslim translators: they describe the punishment in hell of Muhammad and Ali, the founders of Islam. Most Muslim translators choose not to render them in their language (Arabic, Farsi, etc.). The same verses have generated an iconography whose most famous instance is in the cathedral of San Petronio in Bologna. Giovanni da Modena's fifteenth-century fresco depicting Muhammad in hell became the object, at the turn of the twentieth century, of heated tension between local Muslim radical associations, which wanted the fresco to be removed, and Catholic commentators, who defended the integrity of the Christian artistic heritage. Taking as a point of departure these two interconnected case studies, the article explores the difficult role of translation at the conflict-ridden crossroads of different semiotic ideologies.

KEYWORDS Linguistic patterns; Cultural patterns; Semiotic ideology;

Religious sensibility; Semiotic translation

Music falls on the silence like a sense, A passion that we feel, not understand.

Wallace Stevens, Notes Toward a Supreme Fiction (1942)

\section{Patterning the world through language}

According to Danish linguist Louis T. Hjelmslev, language can be conceived as a function between two substances: on the one hand, an expressive substance that manifests content; on the other hand, a content substance that is manifested by expression (1943). Such function takes place because two correllated forms (respectively, the form of expression and that of content) pattern substances. Indeed, according to Hjelmslev, reality before language is just matter; it is either expressive matter, that is, everything that can be used to signify, or content matter, that is, everything that can be signified. Before language, reality is just potentiality. Patterning forms must intervene so as to turn this potentiality into actuality of either expressive or content substance. Forms therefore essentially consist in systems of choices, which essentially are matrixes of inclusion and exclusion.

Whatever is perceptible can be used to signify. For instance, every sound produced by the human 
vocal apparatus may be adopted to manifest content. However, in no human natural language are all these sounds turned into substance of linguistic expression. That is due to several reasons. First of all, the production of sound by the human vocal apparatus is a continuous phenomenon. That means that, in terms of acoustics, differences among sounds are always gradual. We perceive that a sound ' $x$ ' is different from a sound ' $y$ ', but we can always imagine, produce, and hear a sound ' $z$ ', whose difference is intermediate between ' $x$ ' and ' $y$ '. In order for this sound continuum to be used in signification, however, a matrix of inclusions and exclusions must be projected onto such a continuum, in order to transform it into a discrete pattern. The way in which a language excludes or includes sounds in its expressive substance is precisely the expressive form of that language. But why is it thus? Couldn't language indistinctively use all the sounds that the human vocal apparatus is able to produce? That is not the case, because the ultimate purpose of this patterning matrix of inclusions and exclusions is not simply to differentiate between admissible and non-admissible sounds, but to use such a matrix in order to distinguish between admissible and non-admissible thoughts. Indeed, just as whatever is perceptible can be used to signify, so whatever is thinkable can become content of signification. Moreover, just as the sounds produced by the human vocal apparatus form a continuous spectrum, so are thoughts produced by the human mind.

Content difference is no more discrete than expressive difference. Given the distinction between a thought $A$ and a thought $B$, one can always imagine a thought $C$ whose difference is intermediate between $A$ and $B$. However, human beings cannot simply turn into signification whatever is thinkable, and cannot think reality as continuum. They must choose. They must distinguish between what is relevant in their environment and what is not. They must establish a grid of discrete differences. Language is certainly a means of communication among human beings. However, before that and more fundamentally, language is a means of signification among human beings. It allows human beings to differentiate among aspects of reality that are relevant for life, and aspects that are not (Chomsky 2012). Therefore, the expressive matrix patterns the sounds that are produced by the human vocal apparatus because such patterns must be used in order to express the content patterns that human beings impose on reality, and that constitute the content form of their language. The two phenomena can be distinguished only theoretically. Language is that which simultaneously turns reality into a matter of both thought and communication, content and expression.

\section{Variety of patterning matrixes}

Linguists and semioticians realize that language works as a matrix that creates patterns by excluding or including expressive and content elements, because alternative matrixes are possible. Staying within the patterned world shaped at both the expressive and the content level by one's language does not allow one to understand how this language works. It is only through contact with expressive and content patterns generated by alternative matrices that the linguist and the semiotician realize what choices constitute their own 'natural' language. Two orders of variety can be observed in language. On the one hand, as has already been pointed out, language distinguishes between what is relevant in reality and what is not. On the other hand, since reality is not always the same, language must also vary accordingly. Furthermore, language varies not only because reality varies, but also because human beings use language in order to differentiate among groups depending on the relevance that certain aspects of reality have for each of them. Not only do human beings speak different languages because they live in different worlds; they also live in different worlds because they speak different languages. Languages are often relics of past differences, whose subsistence is no longer justified by the relation between human beings and their environment, but by the relation between some groups of human beings and other groups of human beings. Socio-cultural groups that shape 
diverging languages in response to different environments end up affirming their difference through language, even when the environment in which they live has changed and unified. Part of the reason for this inertia of language over reality is that it takes time and energy to adapt to a new linguistic articulation of reality. More significantly, members of the human species seem to be biologically constrained to develop such a linguistic grid of articulation of the world in the first years of life. It is through developing language, and in particular, through learning a natural language, that members of a group absorb and interiorize the traditional way in which that group turns reality into a series of meaningful patterns, often by contrast with the traditional articulations of other groups.

\section{Degrees of variety}

Understanding the variety of patterning matrixes through which human groups articulate their world is relatively simple as regards the multiplicity of expressive forms. For a citizen of Italy, for instance, it is sufficient to travel a few miles to realize that words are pronounced in a different way, that different words are used, and sometimes even to have the experience of not understanding, that is, to have the experience that different languages exist. In some other linguistic contexts, such experience of diversity might not be so immediate. In large communities that have long achieved a high degree of linguistic uniformity, experience of the 'linguistic other' is not as immediate. Nevertheless, realization of the expressive variety of languages is intimately connected with realization of their semantic variety at a fundamental level. When most present-day human beings hear other human beings utter sounds that the former cannot relate to any content whatsoever, they assume that those sounds are, nevertheless, language. In other words, they assume that the way in which human beings whom they do not understand use vocal sounds is analogous to the way in which they themselves use similar sounds in language. Many non-verbal signs contribute to give this impression. Most importantly, we assume that vocal sounds that we do not understand are, nevertheless, language because they seem to allow interactions among human beings that are similar to those that take place through language.

In 1970, the Hungarian novelist Ferenc Karinthy published a novel titled Epepe (2004; English translation Metropole, 2008). It tells the anguishing story of a linguist on his way to a congress in Helsinki who somehow takes the wrong plane and ends up in a city where inhabitants speak a language that is unknown to him. Despite all his efforts, the language remains a mystery to him, and yet he persists in the idea that the incomprehensible sounds that he hears all around, and the indecipherable signs that he sees in the city, are language. Only in a moment of utter despair, when every way out of the city seems precluded to him, is Budai, the protagonist, struck by the terrifying idea that those sounds actually are not language, and that each inhabitant of that city speaks an idiolect. However, the fact itself that citizens interact with each other in a seemingly functional albeit chaotic manner is sufficient to dispel such an anguished thought. Language indeed is potentiality of rational coordination, and potentiality of rational coordination is language.

Attributing linguistic dignity to unknown human sounds is an important element in attributing human dignity tout court. It is fundamental in order to recognize the other, whom I cannot understand, as a fellow human being. Other elements allow this inclusion of the other in the species, but language certainly is one of the most important. That has not always been the case. In the past, for instance, human groups whose language was unknown were called 'barbaric' exactly because they were thought to be less than human, and their vocal sounds judged closer to animal calls than to the sounds of properly human language. Those sounds were articulate enough to distinguish a group as different - exactly as an animal species is often distinguished by its call - but they were not articulate enough to include that group in the human fellowship. In subsequent historical epochs degrading the vocal sounds of another human group and attributing to them an 'animal character' has been and still is a common strategy of 
dehumanization. Symmetrically, assuming that animals cannot communicate among themselves in the same way in which human beings do, and considering the sounds and other utterances that non-human animals produce as less than signs, is one of the greatest obstacles to perceiving the continuity between 'us' and 'them', and stressing, on the contrary, the discontinuity between the human species and the rest of the animal kingdom. Ideology therefore plays a crucial role in experiencing and realizing the existence of alternative matrices and patterns of linguistic expression, since observing the difference of linguistic sounds as linguistic sounds already implies the assumption that the world might be spoken about through different, and sometimes radically diverging languages.

Although realization of the expressive variety of languages is intertwined with realization of the content variety of cultures, the former is more readily accessible than the latter. Realizing that one does not understand the sounds of another language is a more immediate experience than realizing than one does not understand the thoughts of another culture. That is the case because incomprehensible sounds are still audible, and relatively easy to associate with the idea that, although undecipherable, they actually are the expressive side of a language, since they often co-occur together with other signs in human interactions that are therefore recognized as such. Other expressive systems of signification do not give rise to the same 'natural' assumption, especially when they are encountered and observed far from live interactions. Objects that are signifiers in an unknown culture, for instance, may well appear as mere objects, and not as signifiers, when they are encountered as isolated specimens. Rocks that Australian Aborigines use to signify their conception of the world appear as mere rocks to uninformed non-Aborigine observers. In general, the more a signifier is distant from the range of signifiers that we adopt to articulate and project a patterning matrix onto the world, the more difficult is to perceive it as a signifier and not as a mere object.

Experiencing diversity is generally easier at the expressive than at the content level. Articulations of thoughts that are not included in the form that patterns our world are simply invisible to us, or else they are stigmatized as unacceptable, exactly as sounds of a language may not be recognized as such but as barbaric cries, or even as mere noise, by someone who is not familiar with their linguistic nature. Language that human beings interiorize as children becomes a system of naturalized habits not only in the production of signifiers, but also in the production of meaning. Learning how to articulate the sounds of a foreign language might be difficult, or even impossible to many (remember the biblical story of shibboleth); however, learning how to articulate the thoughts of a different culture is harder, since such difference might not even be conceived in the first place. The internalization and naturalization of content patterning matrices is even deeper than the internalization and naturalization of expressive patterning matrices, since the latter are actually instrumental to the former. In many cases, we use different systems of signifiers because we want to express different articulations of reality.

If it is hard to perceive and understand unfamiliar systems of signifiers, it is even harder to do so with regards to unfamiliar systems of content. It is relatively easy for an anthropologist to understand that two societies diverge as regards their articulation of kinship, since kinship systems are usually formalized and expressed through verbal patterning matrices. The analysis of these matrices will therefore immediately reveal difference among the content patterning matrices that they express. However, understanding how different cultures live by diverging articulations of feelings is much harder. In general, the less these content patterns are explicitly signified by verbal language, the harder they will be to grasp.

\section{Typology of Translation Tasks}

Translating between diverging expressive patterns is a relatively easy task. ${ }^{1}$ The hardest challenge that translators face is to detect diverging content patterns that do not explicitly find expression in 
verbal language, but stay implicit or are manifested through other, subtler and more volatile, expressive codes. In this regard, the experience of watching a comic movie in a foreign country is illuminating. Foreign spectators might well be able to understand all the dialogue of the movie. They might also be capable of detecting and decoding the other codes that compose the filmic text, such as acting, editing, lighting, soundtrack, and so on. However, they will probably find out, to their unease, that they do not laugh at the same time that the native audience does, and not with the same rhythm and intensity. Even the most linguistically and culturally competent spectators will have the impression that they do not belong to the audience of that comic movie. They will feel that something separates them from it, something that they should learn to master and, above all, interiorize, in order for the enjoyment of the movie to be complete. That something is not an impressionistic, ungraspable, unfathomable essence. On the contrary, it can be precisely defined in semiotic terms.

In Hjelmslevian terms, two cultures differ not only as regards the different ways in which they articulate the expressive form of verbal language, and for the parallel way in which they pattern reality through a verbal matrix of categorization. Translators know well, for instance, that the English word 'humor' has no ready equivalent in many other languages, and quite often the word is left in English in the translation. However, the most challenging task is not to translate the word, and its visible difference from other words in other languages, but the complex cultural articulation to which the word refers. Translating the word 'humor' is one thing. Translating humor is a completely different, and more difficult, thing. How does a society laugh? On what occasions? About what topics? For or against whom? The way in which a society and its culture laugh result from an extremely complex rhizome of historical and socio-cultural determinations, which translate into a series of 'comic habits' implicitly handed down from generation to generation. We do not learn how to laugh as we learn how to read or write. The cultural form of laughing, in other words, is not explicitly codified into a grammar, taught and learned in schools. Conversely, we learn when and how to laugh through casual exposure to - and spontaneous internalization of - a certain 'laughing style' that surrounds us since birth. The great world comedians, such as Charlie Chaplin or, more recently, Mr. Bean, have been able to make people laugh cross-culturally because they have somehow adopted a comic style resonating with commonalities among different laughing cultures. Other comic styles, instead, which rely more on verbal language or socio-historical references, are impossible to export. The Italian comedian Maurizio Crozza, for instance, is a superstar in Italy. His Friday TV show is one of the most cherished by the Italian audience. However, his humor is so entirely based on irony and sarcasm toward the Italian socio-political panorama that it could never be 'exported' or translated. The most difficult aspect of this translation is not the specificity of the political panorama. Analogous socio-political settings could be found in other societies and provide the context for similar humor. The problem lies elsewhere: not all cultures laugh at their politicians in the way that Italians do. Not in all societies are politicians so prominently protagonists of the social and media imaginaire. The more one moves away from the Italian and especially the European cultural context, the more one will find that people laugh at other categories of people, in different situations and circumstances. Each society, for instance, has a designated category of laughing-stocks for its jokes. For Italians, it is the 'Carabinieri' (a police force); for Spaniards, it is the citizens of Lepe (Huelva); for the French, the laughing-stocks are always the Belgian. Certain features of laughter and humor provoking it are indeed cross-cultural, but others are not, and translating them into another language and culture may prove extremely difficult or even impossible.

Semiotics has long being working on translation, and one of the fathers of the discipline, Umberto Eco, has published a fundamental book on the topic, whose title in English is Saying Almost the Same Thing (Dire quasi la stessa cosa, 2003). The point that the present essay would like to stress is that 'saying the same thing' or, more modestly, 'almost the same thing', is not the most arduous objective in translation, since it essentially bears on finding an equilibrium between explicit, verbal 
patterns of expressive and content articulations. But how can one 'say almost the same thing' if the concept itself of 'thing' varies across cultures? What if the notion of 'almost' varies as well? There are cultures in which approximation is considered as intrinsic to most human endeavors. The Italian culture is certainly one of them. Italians are not usually put off by the fact that a process is near to completion. However, there are other cultures in which a radically different notion of 'almost' and approximation prevails. Languages in these cultures usually have a word to translate the Italian 'quasi' (like in English, 'almost'). The problem is that the semantic aura of this 'almost' is different. 'Saying almost the same thing' can be lightheartedly acceptable in the Italian culture, while being painstakingly and barely tolerated in the German or Japanese one.

That is not to discourage translators or underline the unbridgeable persistence of cultural difference and incommunicability. Eco is perfectly right and, as always, praiseworthy when he seeks to find a rational solution to problems of human communication. At the same time, both translation theorists and translators should acknowledge and be aware of the fact that the difficulty of transposing a text from one language into another language or, more correctly, from one culture into another culture, has different degrees. Again, Hjelmslev's theory of language is ideal to differentiate them.

\section{Isomorphic patterns}

At the easy end of the spectrum of translation challenges, we shall find the task of translating a unit that is explicitly singled out by both the expressive and the content matrix of both source and target verbal language. That is the task that is more commonly associated with the work of translators and it is so simple that in most cases even machines can perform it. The fact that even machines can perform it, though, points out that it is an automatic task, one that does not involve any complex semiotic activity. The word 'cane' in Italian is recognized as a lexical unit (or 'lexeme') by both the expressive and the content matrix of the language. English has an entirely symmetric articulation, so that the English lexeme 'dog' can be straightforwardly used to translate the Italian 'cane'.

\section{Partially isomorphic patterns}

The case in which both the expressive and the content matrices of source and target language are not isomorphic is more complicated. The pair of English lexemes 'home/house', for instance, results from both an expressive and a content articulation that is different, and more complex, than the one that results in the Italian lexeme 'casa'. In this case, translating 'casa' into English will require a choice and, therefore, interpretation, that is, semiotic activity. The translator will have to choose whether the Italian 'casa' refers to a physical place, a 'house', or to an emotional place, 'home'. The opposite translation, from English into Italian, will not require an effort of choice but will entail one of disambiguation: in certain cases, the translator will have to specify whether 'casa' translates 'home' or 'house'. The translator will therefore resort to various strategies, such as periphrasis (for instance, translating 'home' as 'focolare domestico', literally, the 'house hearth'). Google Translator or other similar machines generally perform this task pretty well too, meaning that they are 'intelligent' enough to detect contextual cues that lead to the right choice.

\section{Non-isomorphic patterns}

The case in which the source language contains both an expressive and a content unit of articulation that has no equivalent in the target language is even more complicated. In most instances of 
this type, Google translator and other machines fail, since they cannot rely on any mechanism that automatically retrieves an equivalent in the target language. For instance, if one inputs the Korean word '한' ['han'], Google Translators gives 'one' as output in English. However, such translation would be incorrect when '한' is actually referring to a particular national feeling, which is central in Korean culture, but is absent or radically different in societies that have had a different history. Scholars who want to pinpoint and explain the nature of this feeling must therefore resort to a long periphrasis, which nevertheless fails in rendering the semantic specificity of the word. The English Wikipedia, for instance, needs some long and complex sentences just to give a pale idea of what '한' means: 'a collective feeling of oppression and isolation in the face of insurmountable odds (the overcoming of which is beyond the nation's capabilities on its own). It connotes aspects of lament and unavenged injustice'. When the translator is translating from Korean into Italian a novel that is entirely impregnated with the notion and feeling of '한', the task ahead is very hard. That is so because the way in which the Italian culture articulates the semantic field of feelings is different from the way in which the Korean culture does it. In certain cases, an equivalent or rather a 'quasi-equivalent' can be found. In other cases, on the contrary, the expressive and content matrix of the target language will contain no equivalent or quasi-equivalent. The translator will therefore have to explain the source culture in the target language (through an encyclopedic footnote, for instance) before being able to translate the word.

\section{Invisible patterns}

Nevertheless, an even harder task for a translator is to convey a semantic difference whose roots are deeper than verbal language. In all the three typologies discussed thus far, the expressive matrix of either both languages (in the first two cases), or at least one of them (in the third case) provided explicit clues for the translator to realize and possibly overcome the presence of cultural difference. In the fourth typology, by contrast, difference at the level of content matrices of articulation of reality will not be explicitly manifested by difference at the level of expressive matrices of articulation. This happens especially when cultural difference does not find overt expression in verbal language. If in the third case the translator has to translate a word from the source language that has no equivalent in the target language, in the fourth case, the translator has, at first, to give expression to a semantic peculiarity that is not manifested in the source language either, in order, subsequently, to be able to provide an equivalent, or quasi-equivalent, in the target language, or rather, in the target culture. This fourth kind of translation could be defined as 'anthropological translation', since it does not inhere in the work of the translator but in that of the anthropologist, or rather in the work of the translator as anthropologist.

Saying that translation allows the translator to better know not only the target language, but also the source language, to the point of changing the translator's attitude toward it and the culture it expresses, is true at different levels. There is no particular anthropological discovery in translating 'dog' into 'cane' or vice versa, precisely because this translation must not overcome any significant discrepancy between the two expressive and content matrices. As regards the second type, having to choose between 'house' and 'home', or having to disambiguate the meaning of 'casa', already allows the translator to develop a subtler awareness of how the two languages, and the two cultures, articulate and signify reality. In the third category, the anthropological discovery will be even greater: the translator will either discover the existence of a new feeling (for instance, the Korean " 한') or she/he will discover that this feeling, so central in her/his own culture, is completely absent elsewhere.

The fourth kind of translation, that is, the one requiring the translator to find a suitable expression for a non-manifested cultural unit in her/his own culture before being able to search for an equiva- 
lent, or for a quasi-equivalent, in another culture and language, is definitely the one that should be the most closely associated with the self-discovery aura of translation. In such an operation, indeed, the need to explain one's culture to another culture obliges one to elaborate a verbal articulation of one's own still unexpressed, or poorly expressed, socio-cultural peculiarities. But how can the need for such translation arise in the first place, since it cannot depart from any explicit verbal signification, from any codified expressive unit? Such need arises, most frequently, from an inter-cultural accident. An example will clarify the phenomenological dynamic of this fourth, and most impervious, typology of translation.

\section{Case Study: Translating Outrage}

22 Già veggia, per mezzul perdere o lulla, 23 com' io vidi un, così non si pertugia, 24 rotto dal mento infin dove si trulla. 25 Tra le gambe pendevan le minugia;

26 la corata pareva e 'I tristo sacco

27 che merda fa di quel che si trangugia.

28 Mentre che tutto in lui veder mattacco, 29 guardommi e con le man s'aperse il petto, 30 dicendo: 'Or vedi com' io mi dilacco!

31 vedi come storpiato è Mäometto! 32 Dinanzi a me sen va piangendo Alì, 33 fesso nel volto dal mento al ciuffetto.

$34 \mathrm{E}$ tutti li altri che tu vedi qui, 35 seminator di scandalo e di scisma 36 fuor vivi, e però son fessi così.

37 Un diavolo è qua dietro che n'accisma 38 sì crudelmente, al taglio de la spada 39 rimettendo ciascun di questa risma, 40 quand' avem volta la dolente strada; 41 però che le ferite son richiuse 42 prima chaltri dinanzi li rivada. 43 Ma tu chi se' che 'n su lo scoglio muse, 44 forse per indugiar d'ire a la pena 45 chè giudicata in su le tue accuse?"
No cask ever gapes so wide for loss of mid- or side-stave as the soul I saw cleft from the chin right down to where men fart. Between the legs the entrails dangled. I saw the innards and the loathsome sack that turns what one has swallowed into shit. While I was caught up in the sight of him, he looked at me and, with his hands, ripped apart his chest, saying: 'See how I rend myself, 'see how mangled is Mohammed! Ahead of me proceeds Alì, in tears, his face split open from his chin to forelock. 'And all the others whom you see sowed scandal and schism while they lived, and that is why they here are hacked asunder. A devil's posted there behind us who dresses us so cruelly, putting each of this crew again to the sword as soon as we have done our doleful round. For all our wounds have closed when we appear again before him. 'But who are you to linger on the ridge? perhaps you put off going to the torment pronounced on your own accusation.'

That is the original Italian text of verses 22-45 of Canto XXVIII of Dante Alighieri's Inferno, placed side by side with a recent English translation by Robert and Jean Hollander. The verses describe the position and punishment of Muhammad and Ali in hell. Considered by Dante as 'seminator di scandalo e di scisma', 'sowers of scandal and schism', they are condemned to be perpetually 'fessi', 'hacked asunder'. As Francesco Gabrieli, one of the most acclaimed Italian Orientalists, pointed out in several essays, this passage has given rise to discordant interpretations as regards the attitude of Dante toward Islam.

According to Miguel Asín Palacios - the renowned Spanish Catholic priest and specialist in Arabic studies who, in a famous book, first suggested that Dante might have been influenced by Arabic 
and Islamic sources in composing his Commedia - the passage would actually be a manifestation of Dante's benevolence vis-à-vis Islam. Indeed, from the fact that the Italian poet does not place Muhammad among the heresiarchs, Asín Palacios deduces that Dante judged his sin as social rather than as theological and religious (Asín Palacios 1910: 328). According to most Dante scholars, though, including Francesco Gabrieli, Asín Palacios's interpretation is weak. As Crescini, Zingarelli, Rossi, Fubini, Momigliano, and others have emphasized, the passage in question is one of the crudest and most violent of the entire Inferno. It can hardly be read as a token of Dante's kindheartedness toward Muhammad and Islam.

All these scholars point out that Dante, in depicting Muhammad and Ali in hell as he did, mostly followed medieval tradition, which partly adopted the typical Byzantine anti-Islamic stereotypes and partly created some new clichés (D'Ancona 1912). According to this tradition, variously formulated in several medieval texts, Muhammad has given rise to the 'Islamic schism' encouraged by the rancorous ambition of a disappointed high prelate, variously identified as Sergius, Nicolaus, Pelagius, etc. In some versions, Muhammad himself is described as such a prelate, or even as a cardinal who, disappointed for not having been elected pope, or in order to fulfill various base desires, 'invents' Islam. This tradition, which completely ignores or distorts the historical and theological reality of both the genesis of Islam and its early relation with Christianity, was handed down with little variation to Dante through medieval encyclopedists such as Peter the Venerable, Jacques de Vitry, Martin of Opava, Vincent of Beauvais, Jacobus de Voragine, Brunetto Latini, etc. (Gabrieli 1921: 49-52, 103-4). According to Gabrieli, the scant attention that Dante devotes to the figure of Muhammad - while he dwells on that of his schismatic 'colleague' fra Dolcino, whose historical relevance is incomparably inferior - would be strong evidence of how wrong the hypothesis of Asín Palacios is: Dante, like most of his Christian contemporaries, despised Muhammad (Gabrieli 1965).

The Divine Comedy was first translated into Arabic between 1930 and 1933 by Abbud Abu Rachid, of Lebanese origin and teacher of Italian language and culture in Lebanon and Tripolitania. In his foreword, the translator declares that he refrained from translating the lines on Muhammad. In reality, the lines are not omitted in the translation of Canto XXVIII, but the names of Muhammad and Ali are (Osman 1955). In 1938, Amin Abu Shaar, a lawyer, authored a new translation of the Inferno into Arabic. He omitted Canto XXVIII entirely (ibid). The most acclaimed translation of Dante's Inferno into Arabic to date was completed by the Egyptian philologist Hassan Osman in the 1950s. It also omits the verses of canto XXVIII that bear on Muhammad and Ali (ibid). A translation into Farsi of the Divine Comedy was recently authored by Farideh Mahadavi-Damghani, probably the finest translator of Italian literature into the language of Iran. The translation also omits the lines about Muhammad and Ali. Questioned about this omission on the occasion of the presentation of her translation at a Dante festival in Ravenna, the Tehran-based translator declared: 'My hand does not move to translate these lines; my religious faith as a practicing Muslim does not allow me to act differently. However, I think that it is better to have the Divine Comedy without those verses than not to have it at all' (Bassi 2003, my trans.). Asked whether Iranian readers knew about the missing verses, she replied:

I have given a long explanation to readers about my choice, and I have spoken about Dante as the jewel of jewels. I sought to make people understand that, although those lines were against our religious and spiritual beliefs, the masterpiece was nevertheless worth reading. Furthermore, I have explained that Dante was influenced by medieval scholastics, who certainly knew little about the religion of Islam as a whole. At the time, after the terrible stories of the crusades, people were undoubtedly little inclined to give a positive judgment on Muslims. (Bassi 2003, my trans). 


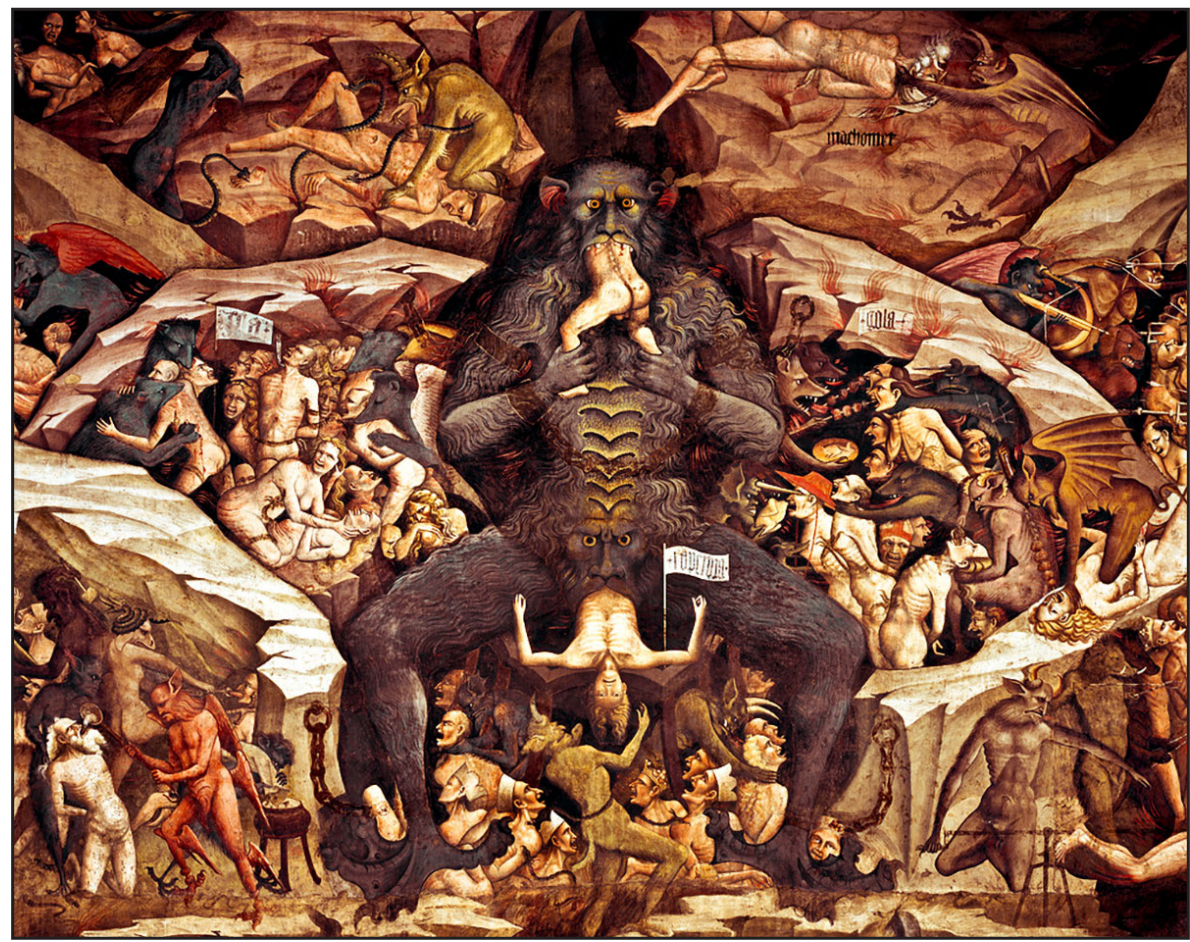

Figure 1. Giovani da Modena, The Inferno (detail), 1410, Cathedral of San Petronio, Bologna

Figure 1 reproduces a fresco that the Italian painter Giovanni da Modena, active from 1408 to 1455, painted to decorate the chapel of the Magi in the Cathedral of San Petronio, in Bologna. The fresco consists in a late Gothic representation of hell, clearly inspired by Dante's Inferno. In his pictorial interpretation of Canto XXVIII, Giovanni da Modena placed Muhammad in the top part of the image, on the immediate right of the monstrous Lucifer. Muhammad is represented as an elderly man with a long beard, naked and tied, lying on a rock while a demon tortures him. Muhammad's identity can be recognized also thanks to the caption 'Machomet' just beneath the pictorial representation of his tormented body.

On November 13, 1998, about a hundred Muslim migrants, mainly from Northern Africa and with regular visas, helped by the Italian members of local radical left-wing groups, occupied the cathedral of San Petronio in order to protest against their sudden eviction from public housing buildings that they had illegally occupied. Contradictory statements by the representatives of the Catholic Church in Italy followed the 23-hour-protest (Corriere della Sera 2002). Ernesto Vecchi, the auxiliary bishop of Bologna, declared that the occupation was 'a gesture of violence against our foremost urban temple. They are Muslims. I wonder what would had happened if Christians had occupied a mosque' (Cavadini, Buifi and Girola 1998, trans. mine). On the contrary, Raffaele Nogaro, the bishop of Caserta, declared that:

one must be able to understand. To realize what it means, to find oneself in the middle of the street, without a roof, not knowing where to go. Therefore, I believe that the first thing to do is to have comprehension for those who end up occupying a church [...] I don't believe that if a Muslim occupies one of our churches because he does not have a place to sleep with his family, others might feel offended in their own religious sensibility. (Cavadini, Buifi and Girola 1998, trans. mine)

Similar protests had occurred throughout the mid-1990s. The most famous one was probably the occupation, in 1996, of the church of Saint Bernard in Paris by the so-called 'sans papier', which attracted extensive media coverage (Simmonot 2002).

However, according to an urban rumor that it is impossible to verify, but whose cultural signifi- 
cance is beyond doubt, it was on November 13, 1998, during the occupation of the Cathedral of San Petronio, that Muslim migrants living in Bologna first saw the depiction of Machomet/Muhammad in the fresco of Giovanni da Modena (Corriere della Sera 2002). On June 30, 2001, about three hundred Muslims demonstrated in front of the main mosque of Bologna, asking that Giovanni da Modena's fresco be removed. Representatives of the Union of Italian Muslims, a small Italian Islamic group often associated with radical initiatives, declared that the fresco represented a 'very serious and unacceptable offense' (Corriere della Sera 2001, trans. mine), and that they had written letters to the Pope and to the bishop of Bologna claiming that the painting 'was blasphemous and obscene and offended Muslims all over the world'. The most prominent Italian Islamic associations condemned this initiative.

However, on June 23, 2002, Italian police officials revealed that 'Amsa the Libyan', reputedly the main emissary of Osama Bin Laden's Al Qaeda in Europe, was planning a terrorist attack against the Cathedral of Saint Petronio, and that investigations by the European police and the consequent arrest of 'Amsa the Libyan' had prevented the attack (Fasano 2002). From then on, the Cathedral began to be under close surveillance by the Italian police. Undercover policemen began to be present in the Cathedral at all times. Two days after these disclosures by the Italian police, Francesco Cossiga, former President of the Italian Republic, known for his provocative initiatives, published a long letter addressed to Giacomo Biffi, the Cardinal of Bologna, in II Resto del Carlino, the main newspaper of the city. In his letter, he invited the Cardinal to:

consider the opportunity of removing from the Cathedral of San Petronio the unsuitable depiction of Muhammad in Hell (it is a dogma, indeed, that we cannot know who really is in hell, except the fallen angels!) in order to keep it in a profane place, limited to its merely artistic values. The modern techniques for transferring paintings can execute the removal marvellously. It would be an exemplary act of tolerance, respect, and tangible attestation of the values of inter-religious dialogue promoted by the Council, which would honor the Diocese of Bologna and the Italian Church; an act of goodwill, which would facilitate relations with the more and more pressing and numerous 'Islamic invasion' of our Country. (Cossiga 2002)

Incidentally, this letter gave rise to an inflamed exchange of letters between Cossiga and the already mentioned Ernesto Vecchi, who was outraged by the former President's proposal. However, on August 21, 2002, the Italian press reported that four young Moroccan migrants, all workers in local factories with regular visas and no criminal records, as well as their Italian chaperon, had been arrested while videotaping Giovanni da Modena's fresco in the Cathedral of San Petronio (Monti 2002). The undercover police had confiscated the videotape, translated the young Moroccans' comments from Berber into Italian, and found that they contained the following declaration: 'That is what they have shown on the TV news. Yes, it's that one. You know what the idol [the idol being Osama Bin Laden] said? If they don't eliminate it, he'll knock everything down' (ibid, trans. mine). The following day, after all the Italian media had largely reported the news, the young Moroccans and their Italian chaperon were acquitted by the competent judge, who had found that their comments on Giovanni da Modena's fresco were not sufficient grounds to accuse them of terrorist plots (Sarzanini 2002).

On March 21, 2006, the Italian press reported the arrest of several young Moroccans and Tunisians accused of planning a terrorist attack against the Cathedral of San Petronio. Following a new policy of the Italian Ministry for Internal Affairs, they were not put on trial, but deported to their countries of origin (Corriere della Sera 2009). In March 2006, an Italian journal associated with Opus Dei, Studi Cattolici, published the following satirical cartoon about Giovanni da Modena's fresco (Fig. 2): 


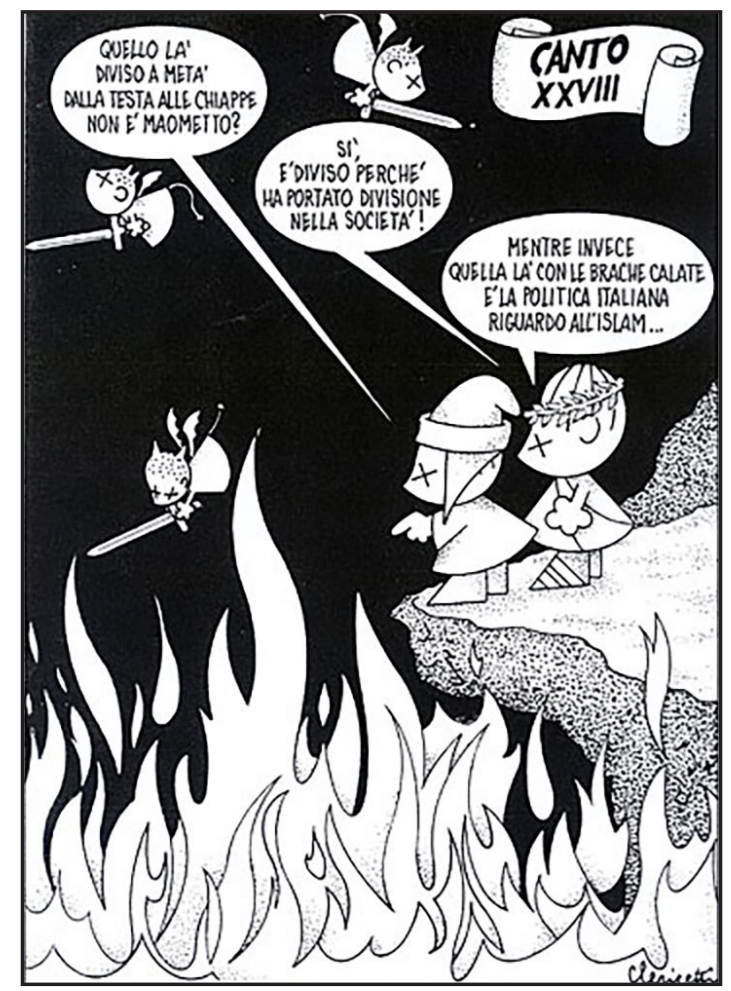

Figure 2. Cartoon published in Studi Cattolici @, March 2006

Dante asks Virgil: 'Isn't the one over there, cut in half from head to cheeks, Muhammad?' And Virgil replies: 'Yes, he is cut in half because he brought about division in society [...] and the one over there with his pants down is Italian politics toward Islam' ('to pull one's pants down' is a not very elegant idiomatic Italian expression meaning 'to chicken out'). Representatives of the Italian Islamic communities as well as most Catholic and secular commentators condemned the cartoons.

\section{Conclusions: The benefits of anthropological translation}

What lesson can a semiotics of anthropological translation draw from such a series of accidents? The semiotic typology of translation difficulties sketched above can be applied to this case study. As regards the translation of the Divine Comedy into Arabic or Farsi, there is no doubt that Dante's text is a challenge to translators not only in these two languages but also in every other idiom. The Divine Comedy is such a harmonious, dense, and multilayered text, at both the expressive and the content level, that it is impossible to fully render it into another language. Only approximations are possible. The case study described above, however, does not concern the first three typologies of our categorization. Translators of Dante's text might encounter medieval Italian words that (1) have an exact equivalent in the target language; (2) have more or fewer equivalents in the target language; (3) have no equivalent in the target language at all. The skillful translator, however, can overcome all these difficulties. Nevertheless, the decision of not translating into Arabic or into Farsi a passage of the Divine Comedy because it contains a humiliating depiction of Muhammad does not result from these three categories of difficulties; it is rather a cultural accident stemming from unarticulated discrepancies between the source language and, above all, between the source culture and the target language, and primarily the target culture. That which does not translate from the former into the latter is not a lexical unit. It is an implicit semiotic ideology. Most members of Western, non-Islamic societies will be shocked at the idea that such a classic as the Divine Comedy might be 'mutilated' by a Muslim translator just for the sake of eliminating derogatory references to the prophet Muhammad that are 
contained in the original text. On the contrary, many members of predominantly Islamic societies, and especially the most fervent among them, will be shocked at the idea that preserving the integrity of a Western text in its Arabic or Farsi translation might entail disseminating a disparaging depiction of the prophet. Who is right?

The purpose of a cultural semiotics of translation is not to pass judgment on this thorny case. It is rather to point out what underpins it. The source of incomprehension is not simply linguistic: both Arabic and Farsi are extremely rich and ancient languages, perfectly endowed to elegantly translate Dante's masterpiece. The source of misunderstanding is not simply cultural either, at least not in the frame of the third typology of translation described above. That which underpins the cultural accident is, instead, a deeper disparity, which bears on the different hierarchy of sociocultural values in the two societies concerned. Respecting in translation the integrity of the text, considered as expression of the individuality of the poet, is the highest value for most Western, secular societies; on the contrary, respecting the image of the founder of the religious community is the most important value for the Muslim reader. The first step in addressing this miscomprehension is therefore that of explicating what is implicit in the two cultural approaches. Both sides, indeed, have a tendency to 'naturalize' their perspectives: on the one hand, it seems absolutely 'natural' not to omit any part of the text when translating it; not doing so is immediately identified and subject to censure. On the other hand, it seems equally 'natural' not to offend the Prophet; translating verses that discredit him is immediately considered as blasphemy.

What is at stake here is not finding a compromise: Dante's lines on Mohammed are either translated or not. One either sides with the perspective of the West or with that of Islam. That is a personal choice, which cannot be discussed, motivated, or advocated in strictly scientific terms. What is at stake is, rather, the possibility of 'seeing' the cultural legitimacy of the other position, while still endorsing one's own. It is exactly in relation to this task that anthropological translation is needed. On the one hand, the translator will have to make the two positions above explicit, as has been done in the last paragraphs. However, the most difficult task ahead is not simply to identify which semiotic ideologies underlie the cultural clash, but to find a way to translate them. How is it possible, for the fervent Muslim, to understand how shocking it is, for a Westerner, that the Divine Comedy might be selectively translated on the basis of religious bias? And, vice versa, how could the Muslim feel outrage at the disparaging representation of Mohammed conveyed to the secular, Western reader of Dante?

Questioned by Italian journalists about the Muslim outcry against the cartoons sarcastically representing Mohammed, the current Pope Francesco Bergoglio recently proposed an interesting inter-cultural, anthropological translation. He could easily have said: 'Imagine if someone published the same cartoons about Jesus'. However, such translation would have been imperfect and ineffective. First, representations of Jesus are not prohibited in Christianity, on the contrary. Second, most predominantly Christian societies, including the Italian one, tolerate sarcastic or even openly blasphemous representations of Jesus. Wittily, the Pope proposed a different translation: 'If someone insults my mother, of course I give him a punch'. This sentence has been read and criticized by some as a justification of violence. That is not going to be discussed here. The interesting aspect of Pope Bergoglio's translation lies elsewhere: when faced with the task of producing an 'anthropological translation' of the Muslim outrage toward 'blasphemous' representations of Muhammad, Pope Francis did not evoke Jesus, but the Italian (or Argentinian, which is pretty much the same) mom. His translation intelligently sought to convey the meaning, and above all the feeling of Muslim outrage by projecting the same passion not onto an object of religious devotion, but onto an object of family devotion. If the former is increasingly dwindling in Italian society, the latter is not. Italians might tolerate that Jesus is insulted, but most will react passionately if their mother is under attack. In order to translate the deeply passionate, and deeply personal, and deeply irrational attachment of Muslims to Muhammad, Pope Bergoglio translated it through finding a similar emotional articulation in another sphere of 
human life, that of family and in particular that of the mother-child relation in Italy. What is of interest here is not to appreciate or condemn the translation in itself (one could argue that both violent devotions, to one's prophet or to one's mother, are to be criticized), but to point out the efficacy of the translation. Even those Italian journalists who disapproved of the Muslim attitude toward 'blasphemy' were led to perceive more clearly the roots of the problem, and the difference of semiotic ideologies underpinning the cultural conflict. For the fervent Muslim, reading Dante's lines about the prophet produces an emotional effect that would be similar to that which the average Italian reader would feel if those lines were about his/her mother. That does not mean that the latter must justify the censorship of the former. Indeed, anthropological translation can and must be performed both ways. For the Muslim reader too should be encouraged to see that the shock that the Western and especially the Italian reader experiences at the idea of a mutilation of the Divine Comedy is similar to that which the Muslim reader would suffer, should a part of the Koran not be translated into Italian because of disparaging references to Christianity, or to Judaism, or to foreigners, or to women.

As we underlined earlier, performing this kind of anthropological translation will not solve the problem. Neither should it be considered as a way of attributing moral legitimacy to the opponent. For most Westerners, it will always be wrong not to entirely translate a text because of religious bias; for most fervent Muslims, it will always be wrong to translate a 'blasphemous' text. Something, nevertheless, can be achieved. Anthropologically translating the outcry of the other, finding a way to see the processes of internalization and 'naturalization' that led to it, does not eliminate either one's own indignation or that of the opponent. Understanding that we internalized our culture does not immediately turn us into cold observers of it. We keep spontaneously living in a language and in a culture even after we have understood how we have absorbed them. However, if an agreement cannot be found in terms of actual contents and practical solutions, anthropological translation, like every good translation, increases both awareness of the deep roots of the other's otherness and self-awareness of the equally deep roots of one's own identity. If reconciliation does not stem from it, at least what results is an enhanced ability to see the other as self at a more abstract level.

We humans do not get angry about the same things, but we get angry in similar ways. ${ }^{2}$ Understanding that is already a step toward defusing anger.

\section{NOTES}

1 The present essay mostly refers to the tradition of semiotic reflection on translation, culminating in Eco 2003.

${ }^{2}$ The dialectic of anthropological invariance and cultural varieties in the emotional structure of anger, as well as in its both verbal and non-verbal representations, would require an in-depth discussion, which is beyond the primary objectives of the present essay. An interesting introduction to a comparative cognitive study of angry reactions is in Kim 2013.

\section{REFERENCES}

Asín Palacios, M. 1919. Escatologia musulmana en la Divina Comedia. Madrid: Imprenta de Estanislao Maestre.

Bassi, Ilda 2003. Intanto il poema sull'aldilà arriva nelle librerie iraniane ma senza i versi 'quasi satanici' su Maometto all'Inferno. Corriere della Sera (September 10): 29. 
Cavadini, Federica, Fulvio Bufi and Edoardo Girola 1998. Basilica liberata, immigrati divisi. Corriere della Sera (September 10): 17.

Chomsky, Noam 2012. The Science of Language: Interviews with James McGilvray. Cambridge and New York: Cambridge University Press.

Corriere della Sera 2001. Affresco offensivo. Corriere della Sera (June 30): 44.

Corriere della Sera 2002. Dante e il supplizio del Profeta: L'affresco gotico contestato. Corriere della Sera (June 23): 23.

Corriere della Sera 2009. Preparavano attentati al metro: Ordinanze per cinque magrebini. Corriere della Sera (June 4): 30.

Cossiga, Francesco 2002. Togliamo quell dipinto: Lettera al Cardinale Giacomo Biffi, online. II Resto del Carlino (25 giugno).

D'Ancona, Alessandro 1912. La leggenda di Maometto in Occidente. Studi di critica e storia letteraria 2: 167-306.

Eco, Umberto 2003. Dire quasi la stessa cosa. Esperienze di traduzione. Milan: Bompiani.

Fasano, Giusi 2002. Al Qaeda, sventato attacco a San Petronio Bologna, il piano stragista preparato da una cellula milanese. Emissario di Bin Laden arrestato in Gran Bretagna. Corriere della Sera (June 23): 5.

Gabrieli, Francesco 1965. Letture e divagazioni dantesche. Bari: Edizioni del Centro Librario.

Gabrieli, Francesco 1984. Maometto. In: Umberto Bosco (ed.), Enciclopedia dantesca. Vol. 3. Rome: Istituto della Enciclopedia Italiana, 815-816.

Gabrieli, Giuseppe 1921. Dante e l'Oriente. Bologna: N. Zanichelli.

Hjelmslev, Luis 1943. Omkring sprogteoriens grundlæggelse. Copenaghen: Ejnar Munksgaard.

Karinthy, Ferenc 2004 [1970]. Epepe. Budapest: K.u.K.

Kim, Sue J. 2013. On Anger: Race, Cognition, Narrative. Austin, TX: University of Texas Press.

Monti Vittorio 2002. Minacce e video in San Petronio: Cinque arresti. Corriere della Sera (August 21): 11.

Osman, Hassan 1955. Dante in Arabic. Annual Report of the Dante Society 73: 47-52.

Sarzanini, Fiorenza 2002. D'Ambrosio frena: niente allarmismi. Corriere della Sera (June 25): 11.

Simmonot, Dominique 2002. Le Souvenir de Saint-Bernard. Libération (September 3). From: http:// www.liberation.fr/evenement/0101423557-le-souvenir-de-saint-bernard [accessed October 29, 2015].

Massimo Leone is Professor of Semiotics, Cultural Semiotics, and Visual Semiotics at the Department of Philosophy, University of Turin, Italy.

Email: massimo.leone@unito.it 